\title{
Safety, efficacy and efficiency of laser-assisted IVF in subfertile mutant mouse strains
}

\author{
Ming-Wen Li, Kristy L Kinchen, Jadine M Vallelunga, Diana L Young, Kaleb D K Wright, \\ Lisa N Gorano, Katherine Wasson and K C Kent Lloyd \\ Mouse Biology Program, School of Veterinary Medicine, University of California, 2795 Second Street, Suite 400, \\ Davis, California 95618, USA \\ Correspondence should be addressed to K C K Lloyd; Email: kclloyd@ucdavis.edu
}

\begin{abstract}
In the present report we studied the safety, efficacy and efficiency of using an infrared laser to facilitate IVF by assessing fertilization, development and birth rates after laser-zona drilling (LZD) in 30 subfertile genetically modified (GM) mouse lines. We determined that LZD increased the fertilization rate four to ten times that of regular IVF, thus facilitating the derivation of 26 of 30 (86.7\%) GM mouse lines. Cryopreserved two-cell stage embryos derived by LZD-assisted IVF were recovered and developed to blastocysts in vitro at the same rate as frozen-thawed embryos derived by regular IVF. Surprisingly after surgical transfer to pseudopregnant recipients the birth rate of embryos derived by LZD-assisted IVF was significantly lower than that of embryos derived by regular IVF. However this result could be completely mitigated by the addition of $0.25 \mathrm{M}$ sucrose to the culture medium during LZD which caused the oocyte to shrink in volume relative to the perivitelline space. By increasing the distance from the laser target site on the zona pellucida, we hypothesize that the hyperosmotic effect of sucrose reduced the potential for laser-induced cytotoxic thermal damage to the underlying oocytes. With appropriate preparation and cautious application, our results indicate that LZD-assisted IVF is a safe, efficacious and efficient assisted reproductive technology for deriving mutant mouse lines with male factor infertility and subfertility caused by sperm-zona penetration defects.

Reproduction (2013) 145 245-254
\end{abstract}

\section{Introduction}

Laboratory mice, especially genetically modified (GM) mouse lines, are important animal models frequently used for biological and biomedical research. IVF has been used as an assisted reproductive technology (ART) to facilitate fertilization, rederivation, colony expansion, strain recovery and rescue, transport and cryopreservation. Despite its advantages over natural mating, IVF is often ineffective when used to manage mice with male factor infertility or exhibiting subfertility caused by genetic modifications (Naz et al. 2009, Noormets et al. 2009, Yan 2009, Kawano et al. 2010, Kohn et al. 2010, Tardif et al. 2010). In these cases ICSI is a suitable alternative ART (Li et al. 2003, Yanagimachi 2005). However, some consider ICSI to be time-consuming, labor-intensive and technically difficult. Furthermore the number of eggs that can be injected per day is rate limiting, making ICSI impractical for routine and/or high-throughput production of embryos. Similarly mechanical zona drilling (Nakagata et al. 1997, Kawase et al. 2002, Kelley 2010) and chemical zona drilling with acidic medium (Gordon \& Talansky 1986, Conover \& Gwatkin 1988, Ahmad et al. 1989) can improve IVF rates in subfertile mouse strains. But zona drilling can also be technically demanding, requiring the use of micropipettes mounted on micromanipulators in order to pierce the zona.

Laser-zona drilling (LZD) has been recognized for being one of the most promising methods to assist IVF in humans and mice (El-Danasouri et al. 1993, Laufer et al. 1993, Antinori et al. 1994, Liow et al. 1996, Kaneko et al. 2006, 2009). LZD has also been used to biopsy the polar body and blastomere for genetic diagnosis of oocytes and embryos (Montag et al. 2004, Harper et al. 2010), to assist embryo hatching (Hammadeh et al. 2011) and to facilitate the injection of embryonic stem cells into morulae or blastocysts to produce GM mice (Plück \& Klasen 2009). Because it is easy to perform LZD can be done with a high level of precision and reproducibility (Schöpper et al. 1999, Tadir \& DouglasHamilton 2007). Although lasers of varying wavelengths $(0.248,0.308,0.337,1.48,2.94 \mu \mathrm{m}$, etc.) have been tested mice and humans the infrared (IR) laser at wavelength $1.45-1.48 \mu \mathrm{m}$ is preferred (Antinori et al. 1994, Rink et al. 1994, Germond et al. 1995, Schöpper et al. 1999, Peters et al. 2006, Kaneko et al. 2009). 
IR lasers at these latter wavelengths allow noncontact, microscope objective-delivered. Access of the laser beam to the target with minimal absorption by the culture dish and aqueous medium. In addition IR lasers are safer to use compared with either u.v. or near-IR lasers (Schöpper et al. 1999, Tadir \& Douglas-Hamilton 2007).

LZD has been shown to significantly increase fertilization rates in mice (El-Danasouri et al. 1993, Enginsu et al. 1995, Germond et al. 1996, Liow et al. 1996, Anzai et al. 2006, Kaneko et al. 2006, 2009, Boersma et al. 2007) and humans (Obruca et al. 1994) with low quality sperm. Mouse embryos derived by LZD-assisted IVF have been shown to develop to the blastocyst stage in vitro at a rate similar to that of embryos derived by regular IVF (El-Danasouri et al. 1993, Enginsu et al. 1995, Kaneko et al. 2009). It has also been reported that LZD-assisted IVF embryos in B6D2F1 and C57BL/6 wildtype mice develop and are born at rates comparable to those derived by regular IVF (Germond et al. 1996, Kaneko et al. 2009). Neither parthenogenetic activation nor polyspermy has been reported as problems (El-Danasouri et al. 1993, Enginsu et al. 1995, Liow et al. 1996, Kaneko et al. 2009) after LZD-assisted IVF.

The significance of cytotoxic thermal damage elicited by the use of lasers for LZD is disputed. In one study (Anzai et al. 2006), sucrose was used to osmotically shrink oocytes relative to the zona pellucida (ZP), thus increasing the perivitelline space (PVS) during LZDassisted IVF to avoid the potential for laser-induced cytotoxic thermal damage to the oocytes. In another study, Kaneko et al. (2006) found no significant difference between varying sucrose concentrations $(0-0.75 \mathrm{M})$ on the development of $\mathrm{C} 57 \mathrm{BL} / 6 \mathrm{~J}$ mouse embryos derived by LZD-assisted IVF using $350 \mathrm{~mW}$ power at $0.45-0.65 \mathrm{~ms}$ pulse duration. In contrast recent studies using a $1.48 \mu \mathrm{m}$ IR laser showed that LZD-assisted IVF in the absence of sucrose leads to significantly lower pup birth rate in $\mathrm{C} 3 \mathrm{HeB} / \mathrm{FeJ}$ and C57BL/6J wildtype mice (Peters et al. 2006, 2009,
Boersma et al. 2007). To date, the number of published studies reporting on the use of LZD-assisted IVF with or without sucrose in humans and animals, especially genetically altered mouse models, is very limited. Considering their popularity and frequent use, it would be of benefit to determine any untoward effects that may limit the use of lasers to facilitate IVF. Therefore, in this report we conducted studies to determine the safety, efficacy and efficiency of LZD-assisted IVF in 30 subfertile GM mouse lines.

\section{Results}

\section{Minimal laser power output for penetrating the ZP using a single pulse}

In our experience, LZD using a single laser pulse at a power sufficient to penetrate the ZP can be performed at a rate of 200-300 oocytes per hour (or less). Not surprisingly, the rate is slower at lower laser power outputs because of the increased time necessary to move the microscope stage to target the zona pellucid twice in order to drill two adjacent holes to effect penetration. Therefore, to determine the minimal power output required to penetrate the zona, we measured the drill hole size and compared it to the thickness of the zona after different durations of laser pulses at $300 \mathrm{~mW}(100 \%$ power) in C57BL/6J mouse oocytes (Figs 1 and 2). Diameters of holes drilled at laser pulse durations of 190, 200, and $210 \mu$ s were less than the thickness (8.7 $\pm 0.16 \mu \mathrm{m} ; n=15)$ of the zona. At these settings, the laser would need to be fired at least twice in order to create two adjacent holes that together penetrated the zona. At $220 \mu \mathrm{s}$, hole sizes $(9.0 \pm 0.09 \mu \mathrm{m})$ were similar to the zona thickness $(P=0.0689)$, but usually did not completely penetrate the zona. Only at a pulse duration $\geq 230 \mu \mathrm{s}$ was the drill hole size (diameter 10.2 $\pm 0.14 \mu \mathrm{m})$ wider than the zona thickness $(P<0.0001)$ and completely penetrated the zona.

We then performed experiments to determine if a single pulse at $230 \mu$ s and at power levels $<100 \%$

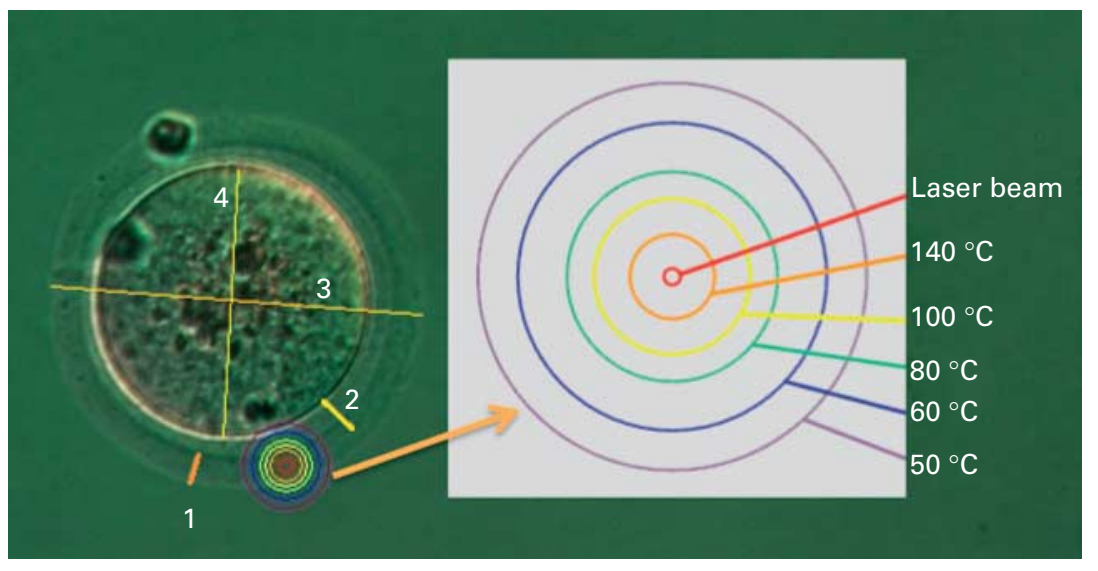

Figure 1 Laser beam targeted on the zona of a C57BL/6 J oocyte showing the location of isotherm rings relative to the oolemma. (1) Zona thickness, (2) distance between the oolemma and the zona center (or laser drill center on the zona), (3) zona diameter, and (4) oocyte cell diameter. The laser isotherm rings appear as a series of six concentric rings of varying colors and indicate the maximum temperature reached at the ring diameter. 


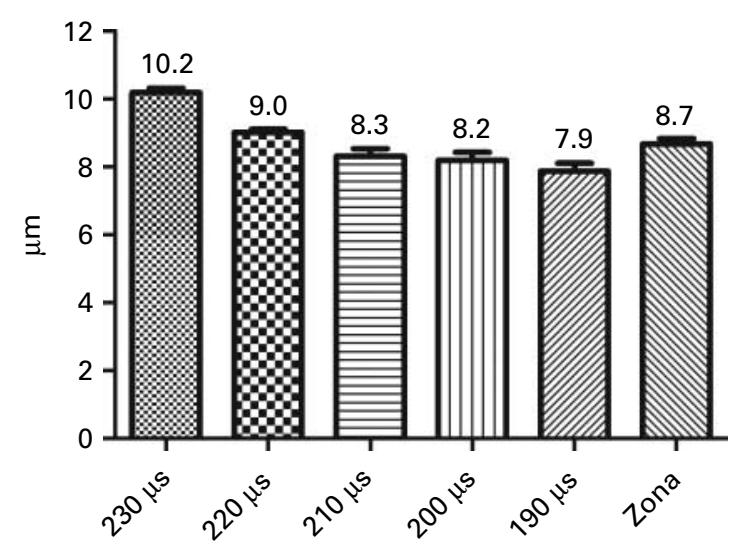

Figure 2 Diameters of holes after different durations of laser pulses at $300 \mathrm{~mW}$ in C57BL/6J mouse oocytes compared with the thickness of zona. Only at a pulse duration $\geq 230 \mu$ s was the drill hole size (diameter $10.2 \pm 0.14 \mu \mathrm{m})$ wider than the zona thickness $(P<0.0001)$ and completely penetrated the zona.

(300 mW) could successfully penetrate the zona (Fig. 3). The diameters of holes produced at $70 \%(210 \mathrm{~mW})$ and $80 \%(240 \mathrm{~mW})$ laser power were significantly $(P<0.0001)$ smaller than the thickness of the zona. By contrast, the average diameter $(7.8 \pm 0.3 \mu \mathrm{m}, n=15)$ of holes produced at $90 \%(270 \mathrm{~mW})$ power was not significantly $(P=0.07)$ smaller than the zona thickness $(8.6 \pm 0.3 \mu \mathrm{m})$, but did not penetrate the zona. Only at $100 \%$ power $(300 \mathrm{~mW})$ and at least $230 \mu$ s duration was a laser pulse minimally effective to drill a hole significantly $(P<0.01)$ large enough to completely penetrate the zona.

\section{Distance between oolemma and the $50^{\circ} \mathrm{C}$ ring at $0,0.25$ and $0.5 \mathrm{M}$ sucrose concentrations}

To minimize potential thermal damage to the underlying oocyte, the laser was always targeted on the zona where the PVS was the widest and at a point on the zona farthest away from the spindle-chromosome complex of the oocyte. C57BL/6) oocytes were exposed to different concentrations of sucrose $(0,0.25$ and $0.5 \mathrm{M}$ ) to determine the distance between the oolemma and the laser drill center on the zona and the distance between the oolemma and the $50{ }^{\circ} \mathrm{C}$ isotherm ring when using a laser pulse of $300 \mathrm{~mW}$ and duration of $230 \mu \mathrm{s}$. As shown in Figs 4 and 5, in the absence of sucrose (0 M sucrose) the oocyte cell diameter was $76 \pm 0.3 \mu \mathrm{m}(n=15)$, and the 50 and $60^{\circ} \mathrm{C}$ isotherm rings overlapped the oolemma when the laser pulse was targeted on the zona. Oocytes exposed to $0.25 \mathrm{M}$ sucrose shrank to a diameter of $65 \pm 0.5 \mu \mathrm{m}(n=15)$, which was significantly smaller $(P<0.0001)$ than that of the oocytes in the absence of sucrose. Oocytes exposed to $0.5 \mathrm{M}$ sucrose shrank even further to a diameter of $57 \pm 0.5 \mu \mathrm{m}(n=15)$, significantly smaller than that at $0.25 \mathrm{M}$ sucrose $(P<0.0001)$.
In medium containing no sucrose and with a laser pulse of $300 \mathrm{~mW}$ and duration $230 \mu \mathrm{s}$, the distance from the oolemma to the laser drill center on the zona was only $10.8 \pm 0.6 \mu \mathrm{m}(n=15)$. Under these conditions the $50{ }^{\circ} \mathrm{C}$ isotherm ring overlapped the oolemma at 1.7 $\pm 0.6 \mu \mathrm{m}$ (Figs 1, 4 and 6). In medium containing $0.25 \mathrm{M}$ sucrose, the distance from the oolemma to the laser drill center on the zona was $20.4 \pm 0.9 \mu \mathrm{m}$, and the oolemma to $50{ }^{\circ} \mathrm{C}$ ring distance was $7.9 \pm 0.9 \mu \mathrm{m} \quad(n=15)$. In medium containing $0.5 \mathrm{M}$ sucrose, the distance from the oolemma to the laser drill center on the zona was further widened $(23.7 \pm 0.6 \mu \mathrm{m})$, and the oolemma to $50{ }^{\circ} \mathrm{C}$ ring was $11.2 \pm 0.6 \mu \mathrm{m}$. In summary exposing oocytes to medium containing $0.25 \mathrm{M}$ sucrose is able to shrink the cells sufficiently to increase the distance of the oolemma from the $50{ }^{\circ} \mathrm{C}$ isotherm ring $(7.9 \pm 0.9 \mu \mathrm{m})$.

\section{Fertilization rates of $L Z D$-assisted IVF vs regular IVF}

In 30 different subfertile GM mouse lines, regular IVF was performed at least three times using one mutant male for each IVF procedure. Poor fertilization rates ( $<15 \%$ of oocytes developed to two-cell stage embryos) were observed consistently for each male in all GM lines. In the same 30 lines, LZD-assisted IVF was then performed at least twice for each GM line. LZD increased fertilization rates more than four to ten times over that after regular IVF $(P<0.05)$ in $26(86.7 \%)$ of 30 GM lines. Fertilization rates using LZD-assisted IVF ranged from 25 to $85 \%$. In four of the $30 \mathrm{GM}$ lines tested, there was no difference in fertilization rate between LZD-assisted IVF and regular IVF (data not shown). Of the 26 GM lines in which LZD-assisted IVF significantly improved fertilization rates compared to regular IVF, three lines were on the $\mathrm{C} 57 \mathrm{BL} / 6 \mathrm{~J}$ genetic background and 23 lines were on the $\mathrm{C} 57 \mathrm{BL} / 6 \mathrm{~N}$ genetic background. The efficiency of LZD-assisted IVF vs regular IVF in 11 subfertile GM mouse lines on $\mathrm{C} 57 \mathrm{BL} / 6$ J and $\mathrm{C} 57 \mathrm{BL} / 6 \mathrm{~N}$ genetic backgrounds is compared in Table 1 .

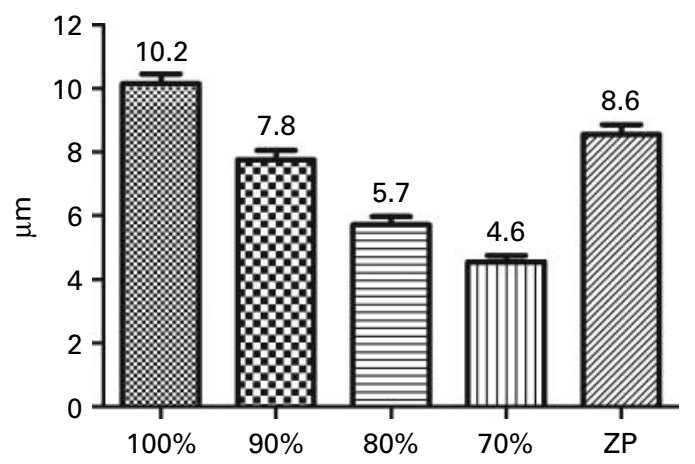

Figure 3 Diameters of holes after different power levels (70-100\%) of laser pulses at $230 \mu \mathrm{m}$ duration compared with the thickness of the zona (ZP, zona pellucida). Only at $100 \%$ power $(300 \mathrm{~mW}$ ) and at least $230 \mu$ s duration was a laser pulse minimally effective to drill a hole significantly $(P<0.01)$ large enough to completely penetrate the zona. 

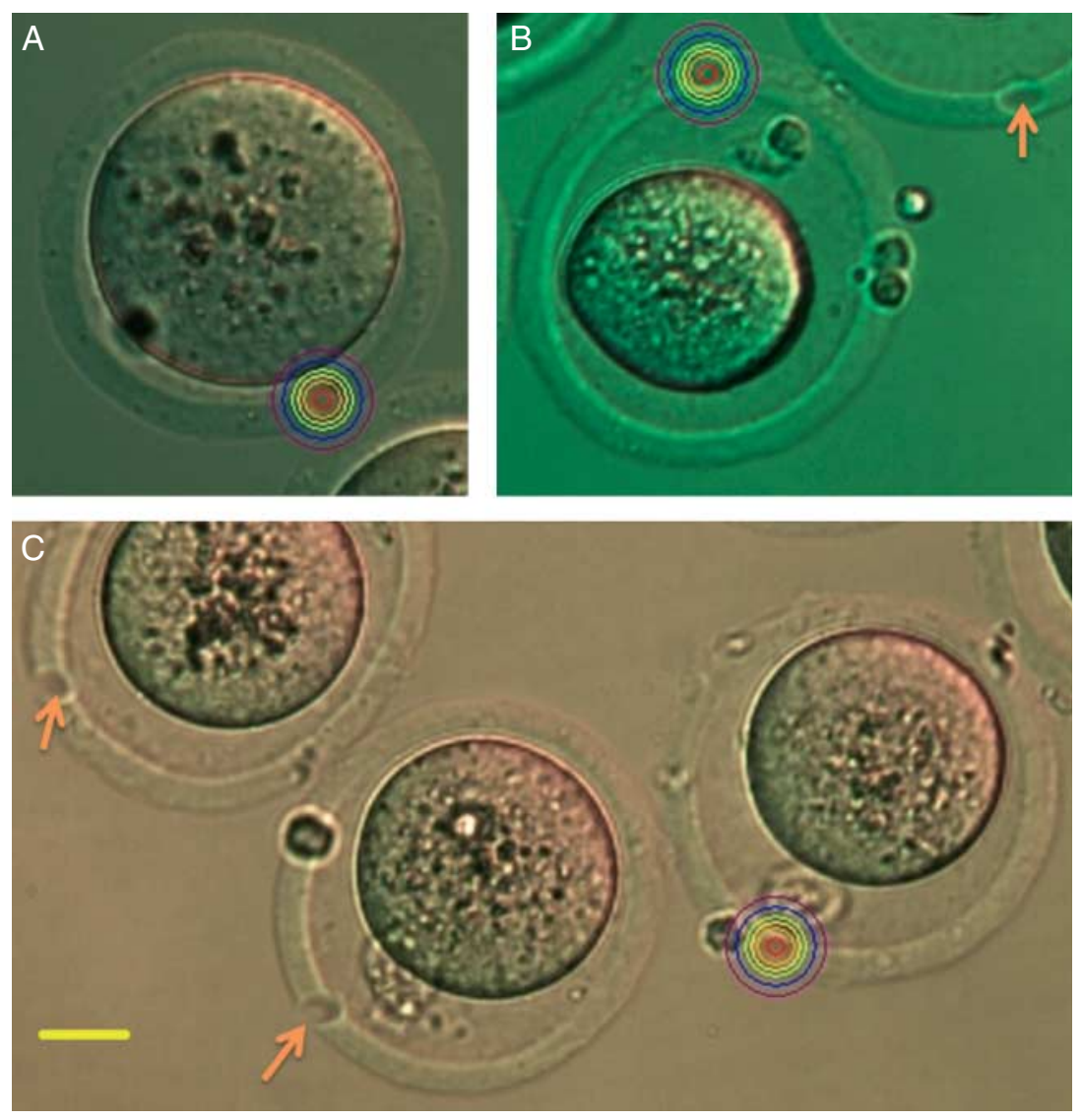

Figure 4 Comparisons of diameters of C57BL/6] oocytes in the absence $(\mathrm{A})$ or presence of sucrose at $0.5 \mathrm{M}$ (B) and $0.25 \mathrm{M}$ (C). Bar $=20 \mu \mathrm{m}$. Arrows, drilled holes.
As shown in Fig. 7, we also compared the efficiency of LZD-assisted IVF vs regular IVF in four GM mouse lines $(A, C$ and $L$ on $C 57 \mathrm{BL} / 6$ ) and $M$ on $C 57 B L / 6 N$ backgrounds) using the same males. For each of the males in these four lines, fertilization rates of LZDassisted IVF were significantly $(P<0.05, n=3)$ higher than that of regular IVF.

\section{Comparison between LZD-assisted IVF and cumulus-free IVF}

To determine the extent to which fertilization rates using LZD-assisted IVF could be enhanced by removing cumulus cells surrounding the oocytes, we compared male-to-male fertilization rates per male for LZD-assisted IVF with regular IVF (using cumulus-oocyte complexes) and unassisted cumulus-free IVF (using cumulus-free oocytes) in nine GM mouse lines (Fig. 8). Males from four lines $(\mathrm{D}, \mathrm{K}, \mathrm{N}$ and $\mathrm{O})$ showed no difference in fertilization rates between cumulus-free IVF and regular IVF $(P>0.05)$, indicating that defective sperm-zona penetration (but not sperm-cumulus penetration) was responsible for subfertility in these four GM lines. Furthermore males from two lines ( $R$ and $S$ ) showed lower fertilization rate when cumulus layers were removed compared with that for regular IVF $(P<0.05)$, also indicating that defective sperm-zona penetration (but not sperm-cumulus penetration) was responsible for subfertility. Furthermore although two lines ( $\mathrm{H}$ and $\mathrm{Q})$ showed an increase in fertilization rates after cumulusfree IVF $(P<0.05)$ compared with regular IVF, the results were still significantly lower than after LZD-assisted IVF $(P<0.05)$. The males in these GM lines exhibited both

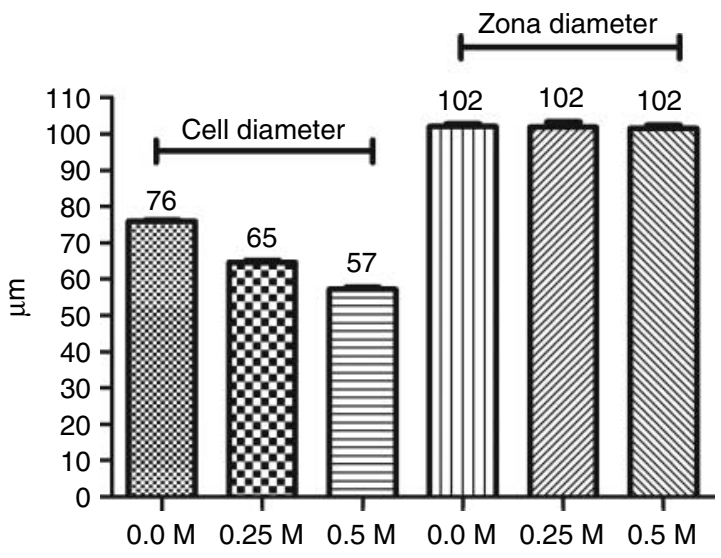

Figure 5 Comparisons of oocyte and zona diameters at different concentrations of sucrose $(0,0.25$ and $0.5 \mathrm{M})$. The oocyte cell diameters decreased significantly $(P<0.05)$ when sucrose concentration was increased from 0 to $0.5 \mathrm{M}$, but the zona diameters remained unchanged $(P>0.05)$. 


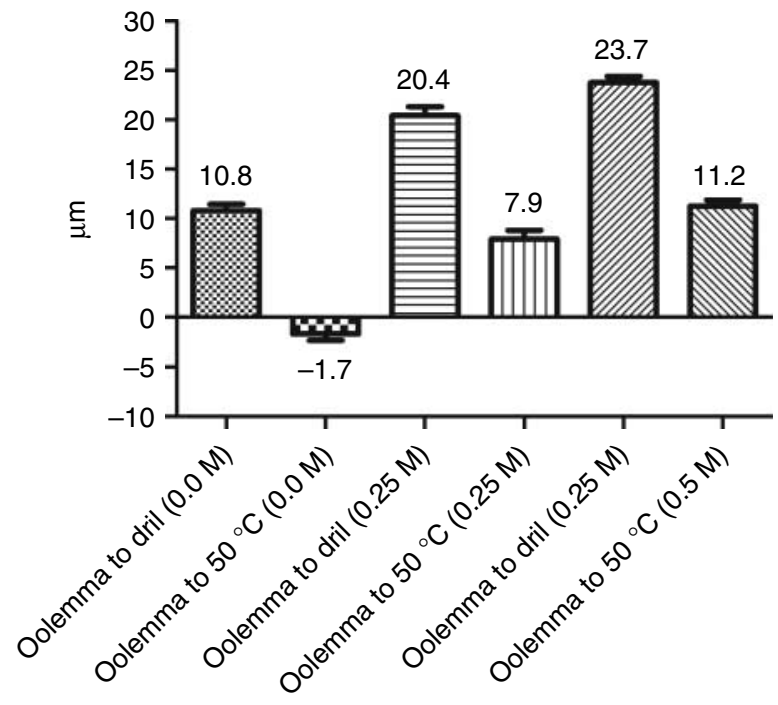

Figure 6 Comparisons of the distance between the oolemma and laser drill center on the zona and between the oolemma and the $50{ }^{\circ} \mathrm{C}$ isotherm ring at different concentrations of sucrose $(0,0.25$ and $0.5 \mathrm{M})$ with a laser pulse of $300 \mathrm{~mW}$ and duration $230 \mu \mathrm{s}$. In the absence of sucrose, the distance between the oolemma and the $50{ }^{\circ} \mathrm{C}$ ring was negative because the ring overlapped the oolemma at $1.7 \pm 0.6 \mu \mathrm{m}$. In the presence of 0.25 and $0.5 \mathrm{M}$ sucrose, this distance was $7.9 \pm 0.9$ and $11.2 \pm 0.6$ respectively.

sperm-cumulus and sperm-zona penetration defects. In only one line $(\mathrm{P})$ was the fertilization rate after cumulusfree IVF increased and equivalent to that of LZD-assisted IVF, indicating that infertility in this line was caused by a sperm-cumulus penetration defect. In all nine GM lines tested, fertilization rates of LZD-assisted IVF were significantly higher than that after regular IVF $(P<0.05)$, and (except in line $P$ ) significantly higher than that after cumulus-free IVF $(P<0.05)$.

\section{In vitro development of embryos derived by LZD-assisted IVF}

To determine the in vitro developmental potential of embryos derived by LZD-assisted IVF compared with embryos derived by regular IVF, frozen-thawed two-cell embryos of $12 \mathrm{GM}$ lines (C57BL/6N genetic background) were cultured to the blastocyst stage in KSOMaa medium (Table 2). No difference was found in blastocyst formation rate between the two groups of embryos $(P>0.05)$.

\section{In vivo development of frozen-thawed embryos derived by LZD-assisted IVF}

In vivo viability and development to term was determined by comparing birth rates (number of pups born divided by the number of two-cell embryos transferred) of embryos derived by LZD-assisted IVF to that of embryos derived by regular IVF in wildtype $\mathrm{C} 57 \mathrm{BL} / 6 \mathrm{~N}$ strain and nine of the $26 \mathrm{GM}$ mouse lines. For these experiments we also assessed the osmotic effects of using sucrose in the medium to protect the oocytes from laser damage (Tables 3 and 4).

In Table 3, results from the use of wildtype C57BL/6N embryos showed that the birth rate of LZD-assisted IVF embryos not treated with sucrose was significantly lower than that of regular IVF embryos $(P<0.05)$. Addition of $0.25 \mathrm{M}$ sucrose to the medium significantly increased the birth rate of LZD-assisted IVF embryos $(P<0.05)$. No significant difference in birth rate was observed between LZD-assisted IVF embryos when using $0.25 \mathrm{M}$ sucrose and regular IVF embryos $(P>0.05)$.

In Table 4, results from the use of embryos of nine GM mouse lines on $\mathrm{C} 57 \mathrm{BL} / 6 \mathrm{~N}$ background were similar to that obtained using wildtype embryos (Table 3). The birth rates of LZD-assisted IVF embryos without sucrose were significantly lower than that of regular IVF embryos. The data also reveal that addition of sucrose to the culture medium greatly increased the birth rate of embryos derived by LZD-assisted IVF in GM mouse lines from 11.5 to $29.7 \%(P<0.0001)$, which was not significantly different from that of regular IVF embryos ( $P>0.05)$.

\section{Discussion}

In the present report, we studied the safety, efficacy and efficiency of LZD-assisted IVF using an IR laser in GM mouse lines. In 26 (86.7\%) of $30 \mathrm{GM}$ mouse lines tested, LZD-assisted IVF was not only safe but also highly

Table 1 Fertilization rates of regular IVF vs LZD-assisted IVF in 11 genetically modified (GM) strains. For mouse lines A, B, and C, C57BL/6J oocytes were used for both regular and LZD-assisted IVF, and for the lines D to K C57BL/6NTac oocytes were used.

\begin{tabular}{llcccc}
\hline Strain & IVF & $\begin{array}{c}\text { No. of GM } \\
\text { males used }\end{array}$ & $\begin{array}{c}\text { No. of } \\
\text { oocytes }\end{array}$ & $\begin{array}{c}\text { No. of } \\
\text { two-cell } \\
\text { embryos }\end{array}$ & $\begin{array}{c}\text { Fertilization } \\
\text { rate } \\
\text { (mean } \pm \text { S.E.M.) }\end{array}$ \\
\hline A & Regular & 4 & 2372 & 131 & $4.8 \pm 1.5$ \\
& Laser & 2 & 594 & 339 & $55.6 \pm 5.2$ \\
B & Regular & 3 & 734 & 84 & $10.4 \pm 4.1$ \\
& Laser & 2 & 478 & 344 & $73.3 \pm 13.3$ \\
C & Regular & 3 & 379 & 17 & $5.7 \pm 2.9$ \\
& Laser & 3 & 293 & 78 & $28.2 \pm 5.9$ \\
D & Regular & 5 & 2003 & 135 & $6.2 \pm 1.1$ \\
& Laser & 2 & 511 & 324 & $61.4 \pm 8.1$ \\
E & Regular & 4 & 2124 & 144 & $6.7 \pm 2.1$ \\
& Laser & 2 & 581 & 316 & $58.7 \pm 17.7$ \\
F & Regular & 3 & 1025 & 54 & $6.2 \pm 2.0$ \\
& Laser & 2 & 589 & 442 & $75.3 \pm 11.5$ \\
$\mathrm{G}$ & Regular & 3 & 1633 & 53 & $4.7 \pm 1.9$ \\
& Laser & 2 & 589 & 393 & $66.7 \pm 9.5$ \\
$\mathrm{H}$ & Regular & 3 & 1157 & 113 & $10.8 \pm 2.1$ \\
& Laser & 3 & 930 & 594 & $62.5 \pm 14.1$ \\
$\mathrm{I}$ & Regular & 4 & 1769 & 86 & $4.5 \pm 1.1$ \\
& Laser & 2 & 938 & 689 & $73.8 \pm 3.3$ \\
$\mathrm{~J}$ & Regular & 3 & 2038 & 87 & $4.2 \pm 1.2$ \\
& Laser & 3 & 692 & 496 & $72.2 \pm 5.1$ \\
$\mathrm{~K}$ & Regular & 3 & 527 & 16 & $2.8 \pm 0.7$ \\
& Laser & 2 & 370 & 169 & $45.1 \pm 2.7$ \\
\hline
\end{tabular}

Number of GM males= number of IVF procedures performed; males used for regular and laser IVF of each GM line were not the same males. The LZD-assisted IVF rate for each strain is significantly higher than that of regular IVF $(P<0.05)$. 


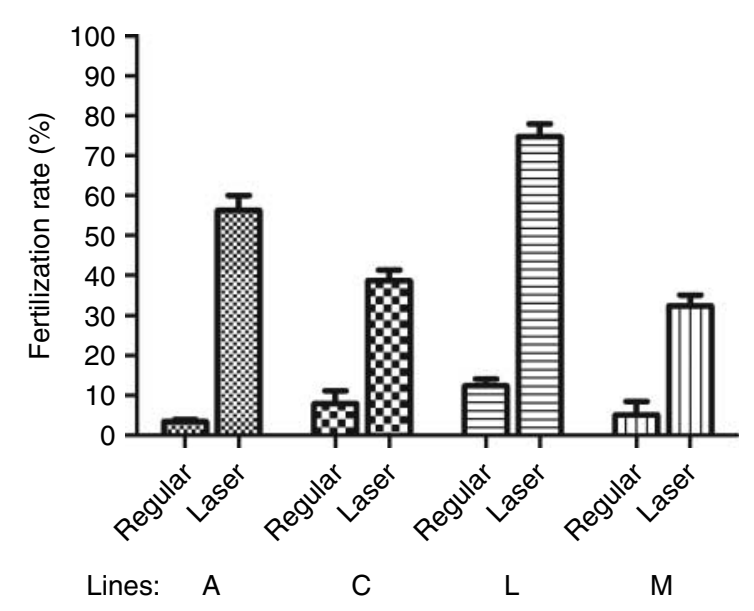

Figure 7 Comparisons of fertilization rates of LZD-assisted IVF vs regular IVF in four GM mouse lines using the same three males of each strain. Experiments were repeated three times, and over 150 oocytes were used for each IVF procedure. Regular vs laser-assisted, $P<0.05$ in each strain.

effective in improving the fertilization rate $\sim 4-10$ times over regular IVF (Table 1 and Figs 7 and 8). These results are consistent with previous reports in mice (El-Danasouri et al. 1993, Enginsu et al. 1995, Germond et al. 1996, Liow et al. 1996, Anzai et al. 2006, Boersma et al. 2007, Kaneko et al. 2009) and humans (Obruca et al. 1994). Our results using LZDassisted IVF and unassisted cumulus-free IVF (Fig. 8) suggest that the lower fertility in most of the GM mouse lines tested was due to an inability of sperm to penetrate the ZP alone or both the cumulus and ZP.

Embryos derived by LZD-assisted IVF developed efficiently to blastocysts in vitro, and there was no difference in blastocyst formation rate found between regular IVF embryos and LZD-assisted IVF embryos (Table 2). These findings are consistent with data reported previously (El-Danasouri et al. 1993, Enginsu et al. 1995, Liow et al. 1996, Kaneko et al. 2009). On the other hand, birth rates of LZD-assisted IVF embryos in both wildtype C57BL/6N (Table 3) and GM lines (Table 4) were significantly lower compared with that of regular IVF embryos, indicating a significant laserinduced cytotoxic effect on embryo development. These results are consistent with previous reports on $\mathrm{C} 3 \mathrm{HeB} / \mathrm{FeJ}$ and $\mathrm{C} 57 \mathrm{BL} / 6 \mathrm{~J}$ wildtype mice that LZD-assisted IVF led to significantly lower pup birth rates (Peters et al. 2006, 2009, Boersma et al. 2007). In contrast reports on B6D2F1 and C57BL/6 wildtype mice showed that LZD-assisted IVF embryos developed normally to liveborn offspring at rates comparable to that of regular IVF embryos (Germond et al. 1996, Kaneko et al. 2006, 2009).

Kaneko et al. (2006) compared the effect of different sucrose concentrations (from 0 to $0.75 \mathrm{M}$ ) on the development of C57BL/6J mouse embryos derived by LZD-assisted IVF. Their results were consistent with no significant laser-induced cytotoxic thermal damage to the embryo, even in the absence of sucrose. The differences between their and our results have several possible explanations. Kaneko et al. (2006) used the Saturn 3 laser system (Research Instruments Ltd., Cornwall, UK) with a laser wavelength of $1.48 \mu \mathrm{m}$ and power of $350 \mathrm{~mW}$ for 450-650 $\mu \mathrm{s}$. In our study, we used a XYClone (Hamilton Thorne Biosciences, Beverly, MA, USA), with a shorter wavelength of $1.45 \mu \mathrm{m}$ and lower power output of $300 \mathrm{~mW}$ for a shorter duration of $230 \mu \mathrm{s}$. In addition, we used RVF medium equilibrated in a $5 \% \mathrm{CO}_{2}$ stage-top incubator during LZD, while Kaneko et al. (2006) used PB1 medium (PBS with BSA, glucose and sodium pyruvate at physiological osmolarity). Although both RVF and PB1 are appropriate culture media, the former's $\mathrm{pH}$ was kept constant in $5 \% \mathrm{CO}_{2}$, while the latter's $\mathrm{pH}$ is unchanged in air. We did not determine which if any of these differences between our and Kaneko's protocols was the cause of our different observations with regard to the beneficial effect of using sucrose during LZD.

The osmotic effect of adding sucrose to the culture medium increased the distance between the oolemma membrane and the ZP thus decreasing the proximity between spindle-chromosome complex as well as other intracellular structures of the oocyte and the point at which the laser pulse was targeted. When $0.25 \mathrm{M}$ sucrose was added to the culture medium to osmotically

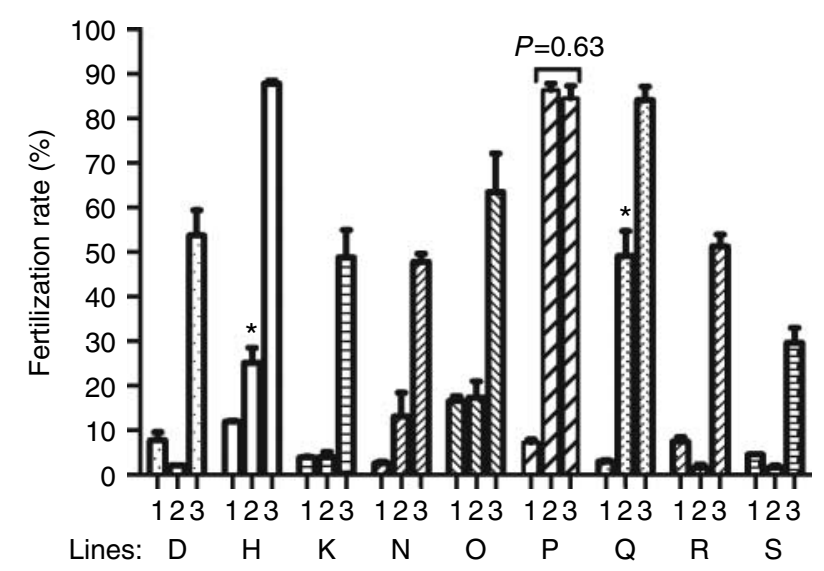

Figure 8 Comparisons of male-to-male fertilization rates of LZD-assisted IVF with unassisted cumulus-free IVF and regular IVF in nine GM mouse lines. (1) Regular IVF, (2) unassisted cumulus-free IVF, and (3) LZD-assisted IVF. Two replicates of experiments were performed for each of the three IVF types in each GM line, and over 100 oocytes were used for each IVF procedure. In all nine GM lines tested fertilization rates of LZD-assisted IVF vs regular IVF, $P<0.05$. Males from $G M$ lines $D, K, N$ and $O$ showed no difference in fertilization rates between cumulus-free IVF and regular IVF, $P>0.05$. Males from GM lines $\mathrm{R}$ and $\mathrm{S}$ showed lower fertilization rate after cumulus-free IVF compared with that of regular IVF, $P<0.05$. Males from GM lines $\mathrm{H}$ and $Q$ showed higher fertilization rates after cumulus-free IVF $(P<0.05)$ compared with regular IVF but still lower than after LZD-assisted IVF $(P<0.05)$. In only $\mathrm{GM}$ line $P$ was the fertilization rate after cumulus-free IVF increased and equivalent to that of LZD-assisted IVF $(P=0.63)$. 
Table 2 In vitro development of frozen-thawed two-cell stage embryos derived by LZD-assisted IVF vs regular IVF in 12 genetically modified (GM) lines on C57BL/6N background. C57BL/6NTac oocytes were used as oocyte donors and they were not treated with sucrose.

\begin{tabular}{lcccc}
\hline IVF method & $\begin{array}{c}\text { No. of GM } \\
\text { lines tested }\end{array}$ & $\begin{array}{c}\text { No. of } \\
\text { embryos } \\
\text { cultured }\end{array}$ & $\begin{array}{c}\text { No. of } \\
\text { blastocysts } \\
\text { obtained }\end{array}$ & $\begin{array}{c}\text { Blastocyst } \\
\text { rate }(\%)\end{array}$ \\
\hline LZD-assisted & 12 & 296 & 193 & $65.9 \pm 2.6$ \\
Regular IVF & 12 & 307 & 219 & $70.9 \pm 1.5$ \\
\hline
\end{tabular}

Embryos derived by LZD-assisted and regular IVF were from the same 12 GM lines; $25-26$ embryos were used in each GM line. There are no significant difference in blastocyst formation rate between the embryos from LZD-assisted IVF and regular IVF $(P>0.05)$. Blastocyst rate $(\%)=$ no. of blastocysts/no. of two-cell embryos cultured.

shrink oocytes during LZD embryos from the nine GM lines tested developed to live born pups at rates similar to that of embryos derived by regular IVF (Table 4). These results are consistent with an earlier report (Anzai et al. 2006) in which embryos derived by LZD-assisted IVF with $0.5 \mathrm{M}$ sucrose using sperm from a subfertile transgenic mouse developed to pups at a rate similar to that of regular IVF embryos. The results of our study indicate that the use of sucrose reduced the risk of laserinduced cytotoxic thermal injury to the oocytes and developing embryo. In addition using sucrose allows one to perform LZD-assisted IVF efficiently by decreasing the amount of time needed to find a laser target point on the zona at a suitable distance from the oolemma.

In summary our results indicate that when using a $1.45 \mu \mathrm{m}$ wavelength IR laser a pulse of $300 \mathrm{~mW}$ at $230 \mu \mathrm{s}$ duration was sufficient to drill a hole slightly wider than the thickness of the ZP. Furthermore these settings are necessary for LZD to penetrate the zona through to the PVS. Our results further indicate that in GM mouse lines, LZD-assisted IVF can be used as a safe, effective, and efficient ART, especially for mice exhibiting male factor infertility and subfertility. With appropriate preparation and due caution, LZD is simple to learn and perform. Furthermore embryos derived by LZD-assisted IVF can be successfully cryopreserved and recovered.

\section{Materials and Methods}

\section{Animals}

All adult male mice for each GM mouse line strain used in this study were obtained from the Mutant Mouse Regional Resource Center (MMRRC) at the University of California (Davis, CA, USA). Oocyte donors were wildtype C57BL/6] mice from the Jackson Laboratory (Bar Harbor, ME, USA) and C57BL/6N mice from Taconic Corporate (Hudson, NY, USA). All mice were housed in a specific pathogen-free vivarium with a $14 \mathrm{~h}$ light/ $10 \mathrm{~h}$ darkness cycle before use. Animal were killed by a combination of $\mathrm{CO}_{2}$ asphyxiation followed by cervical dislocation. The care, use and disposition of all mice used in this study were reviewed and approved by the Institutional Animal Care and Use Committee of University of California at Davis.

\section{Sperm collection and insemination}

Sperm were collected from cauda epididymides of each sexually mature male mouse ( $>12$ weeks old) into $1.0 \mathrm{ml}$ Research Vitro Fert (RVF) medium (Cook Medical Inc., Brisbane, QLD, Australia) under a dissecting microscope, using sterile forceps and syringe needle to hold, pierce and apply pressure to the epididymal tissue to release sperm. Sperm were allowed to disperse for $10 \mathrm{~min}$ in $\mathrm{CO}_{2}$ incubator at $37^{\circ} \mathrm{C}$ followed by assessment for concentration and motility using an IVOS computerized sperm analyzer (Hamilton Thorne). An appropriate amount of sperm suspension in RVF medium was added using a sterile wide-bore tip to $500 \mu \mathrm{l}$ RVF medium drops for IVF, so that the final sperm concentration was about $0.5-1.0 \times 10^{6} / \mathrm{ml}$.

\section{Egg collection}

Female mice (4-6 weeks of age) were superovulated by i.p. injection of $5 \mathrm{IU}$ pregnant mare serum gonadotropin (National Hormone and Peptide Program, Harbor-UCLA Medical Center, Torrance, CA, USA) followed by i.p. injection of $5 \mathrm{IU}$ human chorionic gonadotropin (hCG; Sigma) 47-48 h later. Oocytes were collected $14-15 \mathrm{~h}$ post $\mathrm{hCG}$ injection into warm and preequilibrated RVF medium from oviducts under a dissecting microscope with a warm stage at $37^{\circ} \mathrm{C}$.

\section{IVF}

For each five to eight females, an IVF dish (BD Falcon 1007 Petri Dishes $60 \times 15 \mathrm{~mm}, \mathrm{BD}$ Biosciences, Franklin Lakes, NJ, USA) with a $500 \mu \mathrm{l}$ drop of RVF medium along with $4 \times 100 \mu \mathrm{l}$ drops of RVF medium covered with mineral oil (embryo tested, Sigma) was prepared. Oocyte clutches (masses of cumulusoocyte complexes) collected from five to eight females were added to each $500 \mu \mathrm{l}$ RVF medium drop containing sperm. Sperm and oocytes were cocultured in a $\mathrm{CO}_{2}$ incubator $\left(37^{\circ} \mathrm{C}\right.$, $5-6 \% \mathrm{CO}_{2}$ in air, and $>90 \%$ relative humidity) for $5-6 \mathrm{~h}$. Then oocytes in each IVF drop were picked up and washed through two $100 \mu \mathrm{l}$ drops of RVF medium and then distributed into two $100 \mu \mathrm{l}$ drops of RVF medium in the same dish. The proportion of oocytes developing to two-cell embryos was determined after an overnight incubation $\left(37^{\circ} \mathrm{C}, 5-6 \% \mathrm{CO}_{2}\right.$ in air, and $>90 \%$ relative humidity).

Table 3 In vivo development of fresh C57BL/6N embryos derived by LZD-assisted IVF vs regular IVF.

\begin{tabular}{lccc}
\hline IVF type & $\begin{array}{c}\text { No. of embryos } \\
\text { transferred }\end{array}$ & $\begin{array}{c}\text { No. of } \\
\text { pups born }\end{array}$ & $\begin{array}{c}\text { Birth } \\
\text { rate }(\%)\end{array}$ \\
\hline $\begin{array}{c}\text { LZD-assisted } \\
\text { (no sucrose) }\end{array}$ & 136 & 34 & $24.8 \pm 1.8^{\dagger}$ \\
$\begin{array}{c}\text { LZD-assisted } \\
\quad(0.25 \mathrm{M} \text { sucrose) }\end{array}$ & 134 & 41 & $30.7 \pm 1.5^{\ddagger}$ \\
Regular IVF & 115 & 40 & $34.4 \pm 2.5^{*}$ \\
\hline
\end{tabular}

Birth rate $(\%)=$ no. of pups born/no. of two-cell stage embryos transferred. Experiments were repeated three times using the same three males for different IVF types, and six pseudopregnant recipients were used for each IVF type $(n=6) .{ }^{* \mathrm{vs}^{+}} P<0.05$; t vs ${ }^{\ddagger} P<0.05 ;{ }^{*}$ vs ${ }^{\ddagger} P>0.05$. 
Table 4 Comparisons of birth rates of embryos derived by regular IVF vs LZD-assisted IVF without sucrose or with $0.25 \mathrm{M}$ sucrose in nine genetically modified (GM) mouse lines on C57BL/6N background.

\begin{tabular}{lcccc}
\hline IVF type & $\begin{array}{c}\text { No. of } \\
\text { GM lines }\end{array}$ & $\begin{array}{c}\text { No. of } \\
\text { embryos } \\
\text { transferred }\end{array}$ & $\begin{array}{c}\text { No. of } \\
\text { pups born }\end{array}$ & $\begin{array}{c}\text { Birth } \\
\text { rate }(\%)\end{array}$ \\
\hline $\begin{array}{c}\text { LZD-assisted } \\
\text { (no sucrose) }\end{array}$ & 9 & 165 & 20 & $11.5 \pm 2.2^{+}$ \\
$\begin{array}{c}\text { LZD-assisted } \\
(0.25 \mathrm{M}\end{array}$ & 9 & 210 & 63 & $29.7 \pm 2.5^{*}$ \\
$\quad \begin{array}{l}\text { sucrose) } \\
\text { Regular IVF }\end{array}$ & 9 & 169 & 60 & $35.5 \pm 1.3^{*}$ \\
\hline
\end{tabular}

Birth rate $(\%)=$ no. of pups born/no. of two-cell embryos transferred. Embryos in the three treatment groups were from the same nine GM lines. ${ }^{*}{ }^{\text {vs }}{ }^{+} P<0.0001 ;{ }^{+}$vs ${ }^{\ddagger} P<0.0001 ;{ }^{*}{ }^{\text {vs }}{ }^{\ddagger} P=0.0581$.

\section{Laser-assisted IVF}

Oocyte clutches collected in warm and pre-equilibrated RVF medium were transferred into warm and pre-equilibrated RVF medium containing $\sim 300 \mathrm{U} / \mathrm{ml}$ bovine testis hyaluronidase (Sigma) and incubated at $37^{\circ} \mathrm{C}$ in a $\mathrm{CO}_{2}$ incubator for a few minutes until cumulus cells detached from the oocytes. Denuded oocytes were washed in RVF medium thoroughly and then cultured in this medium before LZD. Before oocytes were used for LZD, they were graded under a dissecting microscope and only the mature oocytes with normal morphology were transferred into the dish for LZD.

An IR laser $(1.45 \mu \mathrm{m}$ wavelength) system (XYClone, Hamilton Thorne Biosciences) coupled with an inverted microscope (Nikon Eclipse TE200), was used for LZD. A single laser pulse was applied once to each oocyte in order to drill a hole through the ZP at different power outputs. LZD was performed on oocytes in $100 \mu$ l RVF medium drops (about 50 good quality oocytes per drop) covered with mineral oil in a culture dish (BD Falcon 1007 Petri dish $60 \times 15 \mathrm{~mm}$ ). The dish was fixed in a $37^{\circ} \mathrm{C}$ glass chamber of a stage top $\mathrm{CO}_{2}$ incubator (Tokai Hit Co. Ltd., Shizuoka-ken, Japan) placed on the stage of an inverted microscope. The stage-top incubator was provided with a flow of $5 \% \mathrm{CO}_{2}$ and $95 \%$ air to maintain the $\mathrm{pH}$ of RVF medium. The laser was targeted on the zona and focused sharply where the underlying PVS was the widest and farthest away from the spindle-chromosome complex within the oocyte. The focus of the zona was adjusted and the presence of the drilled hole in the zona was verified through watching a computer screen connected to the microscope by a digital camera provided by the XYClone system. After laser drilling, oocytes from five to eight females were transferred into a 500- $\mu$ l RVF drop containing sperm that had been cultured for about $1 \mathrm{~h}$ in $\mathrm{CO}_{2}$ incubator. Sperm and oocytes were cocultured in the $\mathrm{CO}_{2}$ incubator $\left(37^{\circ} \mathrm{C}, 5.5 \% \mathrm{CO}_{2}\right.$ in air, and $>90 \%$ relative humidity) for 5 to $6 \mathrm{~h}$, after which the oocytes were washed and incubated in $100 \mu$ l drops of RVF medium as described above. The next morning fertilization was measured by counting the percentage of two-cell embryos.

When sucrose (Sigma, cell culture tested) was used for LZD, oocytes were transferred to preequilibrated RVF medium containing sucrose before LZD and then laser drilled immediately. After laser drilling, the oocytes were washed in warm and preequilibrated RVF medium thoroughly to remove sucrose before they were added to IVF drops as described earlier.

Photos of oocytes were taken under a DIC optic system (Nokon Eclipse TE200 inverted microscope) and the drilled hole size (diameter), zona thickness, cell diameter, zona diameter, and the distance between oolemma and the center of drilled hole were measured using the XYClone software.

\section{Cumulus-free IVF}

The cumulus layers of oocytes were removed by hyaluronidase treatment as described earlier. Denuded oocytes were washed in RVF medium thoroughly and then added to $500 \mu \mathrm{l}$ RVF drops containing sperm that had been cultured for about $1 \mathrm{~h}$ in a $\mathrm{CO}_{2}$ incubator. Sperm and oocytes were cocultured in the $\mathrm{CO}_{2}$ incubator $\left(37^{\circ} \mathrm{C}, 5-6 \% \mathrm{CO}_{2}\right.$ in air and $>90 \%$ relative humidity) for 5-6 h after which the oocytes were washed and incubated in $100 \mu \mathrm{l}$ drops of RVF medium. The next morning fertilization was measured by counting the percentage of two-cell embryos.

\section{Embryo cryopreservation and recovery}

Embryos derived from LZD-assisted IVF and regular IVF were cryopreserved using PROH (1,2-Propanediol, Sigma P-4347) as cryoprotectant (Renard \& Babinet 1984) and a BioCool IV programmable freezer (SP Scientific, Stone Ridge, NY, USA). Briefly, two-cell embryos were equilibrated in 1.5 M PROH in M2 medium (Millipore, Billerica, MA, USA) for 15-20 min at room temperature. Straws containing embryos (20-25 per straw) were placed inside the BioCool freezer chamber containing $100 \%$ ethanol precooled to $-7.5{ }^{\circ} \mathrm{C}$ and kept there for $5 \mathrm{~min}$ before they were seeded. After 5 more min at this temperature, embryos were cooled down to $-30{ }^{\circ} \mathrm{C}$ at $0.3{ }^{\circ} \mathrm{C} / \mathrm{min}$ freezing speed before they were stored in liquid nitrogen until recovery and surgical transfer.

For embryo recovery a straw was thawed in air for $40 \mathrm{~s}$, followed by immersion in distilled water held at room temperature. Embryos in $1.5 \mathrm{M} \mathrm{PROH}$ were expelled and mixed with $1.0 \mathrm{M}$ sucrose expelled from the same straw followed by $5 \mathrm{~min}$ incubation at room temperature $\left(22-25^{\circ} \mathrm{C}\right)$. Then embryos were transferred into $0.5 \mathrm{M}$ sucrose in $\mathrm{M} 2$ medium for $5 \mathrm{~min}$ at room temperature before they were washed in M2 medium and used for embryo culture or embryo transfer.

For embryo culture $100 \mu \mathrm{l}$ drops of KSOM-AA medium (Millipore) covered with mineral oil were used, and the number of embryos cultured in each drop was 15-25. Embryos were cultured at $37{ }^{\circ} \mathrm{C}$ in humidified $5 \% \mathrm{CO}_{2}$ in air for $96 \mathrm{~h}$ for blastocyst formation rate.

\section{Surgical embryo transfer}

For in vivo experiments embryos at the two-cell stage were transferred into the oviducts (10-12 for each oviduct, and 20-25 per recipient) of 0.5 days post coitum pseudopregnant CD-1 recipients anesthetized with 1.25\% Avertin (Sigma). After 45-60 min anesthesia, $0.1 \mathrm{ml}$ Buprenex $(0.03 \mathrm{mg} / \mathrm{ml}$; Western Medical Supply, Inc., Arcadia, CA, USA) was 
administered subcutaneously in the flank of each mouse postoperatively. Recipients were kept warm on a heating pad until fully recovered from anesthesia. All pregnant recipients were allowed to go to term and give birth to litters for analysis. The health and number of pups born per litter were checked and counted at 21 days after birth.

\section{Statistical analysis}

GraphPad Prism 5 software (GraphPad Software, Inc., San Diego, CA, USA) was used for statistical analysis. Data on fertilization rates, blastocyst formation rates and pup birth rates were arcsine transformed (Ostermeier et al. 2008), and treatment differences were detected by Student's $t$-test. $P<0.05$ was chosen as an indication of statistical significance. Data are expressed as mean \pm s.E.M.

\section{Declaration of interest}

The authors declare that there is no conflict of interest that could be perceived as prejudicing the impartiality of the research reported.

\section{Funding}

This research was funded by NIH/OD U42, Award No. U42OD012210 supporting the Mutant Mouse Regional Resource Center (MMRRC) at UC Davis and by the UC Davis Mouse Biology Program.

\section{References}

Ahmad T, Conover JC, Quigley MM, Collins RL, Thomas AJ \& Gwatkin RB 1989 Failure of spermatozoa from T/t mice to fertilize in vitro is overcome by zona drilling. Gamete Research 22 369-373. (doi:10.1002/ mrd.1120220403)

Antinori S, Versaci C, Fuhrberg P, Panci C, Caffa B \& Gholami GH 1994 Seventeen live births after the use of an erbium-yytrium aluminum garnet laser in the treatment of male factor infertility. Human Reproduction 9 1891-1896.

Anzai M, Nishiwaki M, Yanagi M, Nakashima T, Kaneko T, Taguchi Y, Tokoro M, Shin SW, Mitani T, Kato $\mathbf{H}$ et al. 2006 Application of laserassisted zona drilling to in vitro fertilization of cryopreserved mouse oocytes with spermatozoa from a subfertile transgenic mouse. Journal of Reproduction and Development 52 601-606. (doi:10.1262/jrd.18040)

Boersma A, Marschall S \& Hrabe de Angelis M 2007 Laser-assisted IVF - an alternative approach for successful cryopreservation of mutant mouse lines on $\mathrm{C} 57 \mathrm{BL} / 6$ background. International Mouse Genome Conference, Kyoto, Japan, October 28-November 1, 2007, P77.

Conover JC \& Gwatkin RB 1988 Fertilization of zona-drilled mouse oocytes treated with a monoclonal antibody to the zona glycoprotein, ZP3. Journal of Experimental Zoology 247 113-118. (doi:10.1002/jez. 1402470115)

El-Danasouri I, Westphal LM, Neev Y, Gebhardt J, Louie D \& Berns MW 1993 Zona opening with $308 \mathrm{~nm} \mathrm{XeCl}$ excimer laser improves fertilization by spermatozoa from long-term vasectomized mice. Human Reproduction 8 464-466.

Enginsu ME, Schütze K, Bellanca S, Pensis M, Campo R, Bassil S, Donnez J \& Gordts S 1995 Micromanipulation of mouse gametes with laser microbeam and optical tweezers. Human Reproduction 10 1761-1764.

Germond M, Nocera D, Senn A, Rink K, Delacrétaz G \& Fakan S 1995 Microdissection of mouse and human zona pellucida using a 1.48microns diode laser beam: efficacy and safety of the procedure. Fertility and Sterility 64 604-611.
Germond M, Nocera D, Senn A, Rink K, Delacretaz G, Pedrazzini T \& Hornung JP 1996 Improved fertilization and implantation rates after nontouch zona pellucida microdrilling of mouse oocytes with a 1.48 micron diode laser beam. Human Reproduction 11 1043-1048. (doi:10.1093/ oxfordjournals.humrep.a019294)

Gordon JW \& Talansky BE 1986 Assisted fertilization by zona drilling: a mouse model for correction of oligospermia. Journal of Experimental Zoology 239 347-354. (doi:10.1002/jez.1402390306)

Hammadeh ME, Fischer-Hammadeh C \& Ali KR 2011 Assisted hatching in assisted reproduction: a state of the art. Journal of Assisted Reproduction and Genetics 28 119-128. (doi:10.1007/s10815-010-9495-3)

Harper JC, Coonen E, De Rycke M, Harton G, Moutou C, Pehlivan T, Traeger-Synodinos J, Van Rij MC \& Goossens V 2010 ESHRE PGD Consortium data collection X: cycles from January to December 2007 with pregnancy follow-up to October 2008. Human Reproduction 25 2685-2707. (doi:10.1093/humrep/deq228)

Kaneko T, Yanagi M, Nakashima T \& Nakagata N 2006 The improvement in fertilizing ability of cryopreserved mouse spermatozoa using lasermicrodissected oocytes. Reproductive Medicine and Biology 5 249-253. (doi:10.1111/j.1447-0578.2006.00149.x)

Kaneko T, Fukumoto K, Haruguchi Y, Kondo T, Machida H, Koga M, Nakagawa Y, Tsuchiyama S, Saiki K, Noshiba S et al. 2009 Fertilization of $\mathrm{C} 57 \mathrm{BL} / 6$ mouse sperm collected from cauda epididymides after preservation or transportation at 4 degrees $C$ using laser-microdissected oocytes. Cryobiology 59 59-62. (doi:10.1016/j.cryobiol.2009.04.006)

Kawano N, Kang W, Yamashita M, Koga Y, Yamazaki T, Hata T, Miyado K \& Baba T 2010 Mice lacking two sperm serine proteases, ACR and PRSS21, are subfertile, but the mutant sperm are infertile in vitro. Biology of Reproduction 83 359-369. (doi:10.1095/biolreprod.109.083089)

Kawase Y, Iwata T, Ueda O, Kamada N, Tachibe T, Aoki Y, Jishage KI \& Suzuki H 2002 Effect of partial incision of the zona pellucida by piezo-micromanipulator for in vitro fertilization using frozen-thawed mouse spermatozoa on the developmental rate of embryos transferred at the 2-cell stage. Biology of Reproduction 66 381-385. (doi:10.1095/ biolreprod66.2.381)

Kelley KA 2010 Enhancement of IVF in the mouse by zona-drilling. Methods in Enzymology 476 229-250. (doi:10.1016/S0076-6879(10)76013-4)

Kohn MJ, Sztein J, Yagi R, DePamphilis ML \& Kaneko KJ 2010 The acrosomal protein Dickkopf-like 1 (DKKL1) facilitates sperm penetration of the zona pellucida. Fertility and Sterility 93 1533-1537. (doi:10.1016/ j.fertnstert.2009.06.010)

Laufer N, Palanker D, Shufaro Y, Safran A, Simon A \& Lewis A 1993 The efficacy and safety of zona pellucida drilling by a 193-nm excimer laser. Fertility and Sterility 59 889-895.

Li MW, McGinnis L, Zhu L, Lawitts J, Biggers J \& Lloyd KC 2003 Intracytoplasmic sperm injection (ICSI) enables rescue of valuable mutant mouse strains. Comparative Medicine 53 265-269.

Liow SL, Bongso A \& Ng SC 1996 Fertilization, embryonic development and implantation of mouse oocytes with one or two laser-drilled holes in the zona, and inseminated at different sperm concentrations. Human Reproduction 11 1273-1280. (doi:10.1093/oxfordjournals. humrep.a019371)

Montag M, van der Ven K, Dorn C \& van der Ven H 2004 Outcome of laser-assisted polar body biopsy and aneuploidy testing. Reproductive Biomedicine Online 9 425-429. (doi:10.1016/S1472-6483(10)61278-3)

Nakagata N, Okamoto M, Ueda O \& Suzuki H 1997 Positive effect of partial zona-pellucida dissection on the in-vitro fertilizing capacity of cryopreserved $\mathrm{C} 57 \mathrm{Bl} / 6 \mathrm{~J}$ transgenic mouse spermatozoa of low motility. Biology of Reproduction 57 1050-1055. (doi:10.1095/biolreprod57.5. 1050)

Naz RK, Engle A \& None R 2009 Gene knockouts that affect male fertility: novel targets for contraception. Frontiers in Bioscience 14 3994-4007. (doi:10.2741/3507)

Noormets K, Kõks S, Kavak A, Arend A, Aunapuu M, Keldrimaa A, Vasar E \& Tillmann V 2009 Male mice with deleted Wolframin (Wfs1) gene have reduced fertility. Reproductive Biology and Endocrinology 782. (doi:10.1186/1477-7827-7-82)

Obruca A, Strohmer H, Sakkas D, Menezo Y, Kogosowski A, Barak Y \& Feichtinger W 1994 Use of lasers in assisted fertilization and hatching. Human Reproduction 9 1723-1726. 
Ostermeier GC, Wiles MV, Farley JS \& Taft RA 2008 Conserving, distributing and managing genetically modified mouse lines by sperm cryopreservation. PLOS ONE 3 e2792. (doi:10.1371/journal.pone. 0002792)

Peters DD, Marschall S, Mahabir E, Boersma A, Heinzmann U, Schmidt J \& Hrabé de Angelis M 2006 Risk assessment of mouse hepatitis virus infection via in vitro fertilization and embryo transfer by the use of zonaintact and laser-microdissected oocytes. Biology of Reproduction $\mathbf{7 4}$ 246-252. (doi:10.1095/biolreprod.105.045112)

Peters DD, Lepikhov K, Rodenacker K, Marschall S, Boersma A, Hutzler P, Scherb H, Walter J \& de Angelis MH 2009 Effect of IVF and laser zona dissection on DNA methylation pattern of mouse zygotes. Mammalian Genome 20 664-673. (doi:10.1007/s00335-009-9227-0)

Plück A \& Klasen C 2009 Generation of chimeras by microinjection. Methods in Molecular Biology 561 199-217.

Renard JP \& Babinet C 1984 High survival of mouse embryos after rapid freezing and thawing inside plastic straws with 1-2 propanediol as cryoprotectant. Journal of Experimental Zoology 230 443-448. (doi:10.1002/jez.1402300313)

Rink K, Delacrétaz G, Salathé R, Senn A, Nocera D, Germond M \& Fakan S $19941.48 \mu \mathrm{m}$ diode laser microdissection of the zona pellucida of mouse zygotes. Proceedings of SPIE 2134A 412-422.
Schöpper B, Ludwig M, Edenfeld J, Al-Hasani S \& Diedrich K 1999 Possible applications of lasers in assisted reproductive technologies. Human Reproduction 14 (Suppl 1) 186-193. (doi:10.1093/humrep/14. suppl_1.186)

Tadir Y \& Douglas-Hamilton DH 2007 Laser effects in the manipulation of human eggs and embryos for in vitro fertilization. Methods in Cell Biology 82 409-431.

Tardif S, Akrofi AS, Dass B, Hardy DM \& MacDonald CC 2010 Infertility with impaired zona pellucida adhesion of spermatozoa from mice lacking TauCstF-64. Biology of Reproduction 83 464-472. (doi:10.1095/ biolreprod.109.083238)

Yan W 2009 Male infertility caused by spermiogenic defects: lessons from gene knockouts. Molecular and Cellular Endocrinology 306 24-32. (doi:10.1016/j.mce.2009.03.003)

Yanagimachi R 2005 Intracytoplasmic injection of spermatozoa and spermatogenic cells: its biology and applications in humans and animals. Reproductive Biomedicine Online 10 247-288. (doi:10.1016/S14726483(10)60947-9)

Received 26 November 2012

Accepted 8 January 2013 